\title{
Postoperative bleeding after gastric endoscopic submucosal dissection in patients receiving antithrombotic therapy
}

\author{
Tsukasa Furuhata $^{1} \cdot$ Mitsuru Kaise $^{1} \cdot$ Shu Hoteya ${ }^{1} \cdot$ Toshiro Iizuka $^{1} \cdot$ \\ Akihiro Yamada $^{1} \cdot$ Kosuke Nomura $^{1}$ ' Yasutaka Kuribayashi ${ }^{1} \cdot$ Daisuke Kikuchi $^{1}$. \\ Akira Matsui $^{1} \cdot$ Osamu Ogawa $^{1} \cdot$ Satoshi Yamashta $^{1} \cdot$ Toshifumi Mitani $^{1}$
}

Received: 4 November 2015/Accepted: 21 December 2015/Published online: 11 January 2016

(C) The International Gastric Cancer Association and The Japanese Gastric Cancer Association 2016

\begin{abstract}
Background and aims It is controversial whether antithrombotic therapy increases the risk of bleeding after endoscopic submucosal dissection (ESD). The aim of this study was to evaluate the effects of antithrombotic therapy on gastric ESD.

Methods Patients who underwent gastric ESD at Toranomon Hospital between April 2005 and July 2014 were enrolled. The risk of post-ESD bleeding was evaluated by multivariate logistic regression analysis.

Results Of 1781 patients enrolled, 253 were taking an antithrombotic; 186 discontinued taking a single antithrombotic $(n=150)$ or multiple antithrombotics $(n=36)$ before ESD, whereas 15 continued taking a single antiplatelet agent and another 52 switched to heparin alternative therapy during the peri-ESD period. Post-ESD bleeding occurred in 101 patients (5.7\%): 68 patients $(3.8 \%)$ who did not take an antithrombotic, 11 patients (7.3\%) who discontinued taking a single antithrombotic, six patients $(16.7 \%)$ who discontinued taking multiple antithrombotics, one patient $(6.7 \%)$ who continued taking a single antiplatelet agent, and 15 patients $(28.8 \%)$ who switched to heparin therapy. In multivariate analysis, heparin alternative therapy [odds ratio (OR) 10.04, $95 \%$ confidence interval (CI) 4.35-23.16], discontinuation of the use of multiple antithrombotics before ESD (OR 5.44, $95 \%$ CI 2.00-14.79), tumor location in the lower third of the stomach (OR 2.17, $95 \%$ CI: 1.32-3.58), and a long procedure time (100 min or greater; OR $2.00,95 \%$ CI
\end{abstract}

Tsukasa Furuhata

furuhatahpcom@yahoo.co.jp

1 Department of Gastroenterology, Toranomon Hospital, 2-2-2 Toranomon, Minato-ku, Tokyo 105-8470, Japan
1.25-3.20) were independent risk factors for post-ESD bleeding. Among 52 subjects who switched to heparin therapy, one developed acute renal infarction and one developed cerebral bleeding.

Conclusions Because heparin alternative therapy significantly increases the risk of post-ESD bleeding and may not decrease the risk of thromboembolic events, other options should be considered for patients receiving anticoagulation therapy.

Keywords Endoscopic submucosal dissection . Antithrombotic · Heparin · Gastric tumor

\section{Introduction}

Endoscopic submucosal dissection (ESD) is accepted as a highly curative resection for early gastric cancer without metastasis. Compared with endoscopic mucosal resection, ESD has curative advantages because of the high rate of R0 resection, even in patients with ulceration or difficult gastric location [1-5]. However, in contrast with its superior curability, ESD is associated with higher rates of procedure-related complications; this remains an important issue to be resolved.

The rate of post-ESD bleeding in the stomach has been reported to range between 0 and $15.6 \%$ [6,7], which is higher than the rate of post-ESD bleeding in the colon $(1.5-6.6 \%)$ [7-11] and esophagus $(0-5.2 \%)$ [7, 12, 13]. Previous studies have shown that tumor location, size, and noncoagulated vessels exposed on the ESD ulcer bed are significantly associated with a higher rate of post-ESD bleeding in the stomach [14-16]. However, there are conflicting reports as to the relationship between the use of antithrombotic agents and post-ESD bleeding. For 
example, Lim et al. [17] reported that there was no significant independent association between continuous administration of antiplatelet drugs and post-ESD bleeding; however, Koh et al. [18] reported that antithrombotic therapy was an independent risk factor for delayed bleeding. Moreover, there are no informative data on the relationship between post-ESD bleeding and anticoagulants such as warfarin and heparin, which, given their pharmacological action, would be thought likely to increase the rate of post-ESD bleeding. Therefore, endoscopists face the practical difficulty of deciding how best to manage patients taking anticoagulants during the gastric ESD perioperative period

The aim of the present study was to evaluate the effects of different types of antithrombotic therapy on bleeding after gastric ESD, with particular emphasis on patients who were switched to heparin therapy as an alternative to anticoagulant therapy.

\section{Methods}

\section{Subjects}

Patients who underwent gastric ESD at Toranomon Hospital between April 2005 and July 2014 were enrolled in the present study, with the exception of patients with a history of upper gastrointestinal tract surgery, including esophagectomy or gastrectomy. Patients were also excluded from the study if ESD was performed simultaneously in two or more portions of the stomach. Indications for ESD were based on endoscopic and pathologic findings. To investigate potential risk factors for postoperative bleeding after ESD, the following variables were analyzed: age, sex, comorbidities that could affect bleeding (e.g., central neurological disease, pulmonary disease, cardiovascular disease, renal disease, hepatic disease, hypertension, and diabetes mellitus), the use of antithrombotic agents (continued use of antiplatelet agents, discontinuation of use of a single antithrombotic agent or multiple antithrombotic agents, heparin alternative therapy), the maximum diameter of the resected specimen (less than $20 \mathrm{~mm}$ or $20 \mathrm{~mm}$ or more), tumor location (upper, middle, or lower third of the stomach), pathologic factors (cancer or adenoma, histologic depth, ulcer presence), and operation time. The indications for ESD were determined on the basis of endoscopic findings, including chromoendoscopy with indigo carmine dye, and biopsy. The criteria for gastric ESD used at Toranomon Hospital are those published by the Japanese Gastric Cancer Association [19]. All patients provided written informed consent to undergo the proposed procedure. The study itself was approved by the hospital Ethics Committee.

\section{ESD procedure}

The ESD procedure was performed with a hook knife (KD620LR; Olympus Medical Science, Tokyo, Japan), a flex knife (KD-630L; Olympus Medical Science), and a dual knife (KD-650Q; Olympus Medical Science) through a two-channel scope equipped with multibending and water jet functions (GIF-2TQ260 M; Olympus Medical Science) or a single-channel endoscope (Q260 J Olympus Medical Science). A soft transparent hood (D-201-13404; Olympus Medical Science) was attached to the tip of the endoscope to obtain good, direct endoscopic views of the submucosal layer. Marker dots were placed on the normal mucosa approximately $5 \mathrm{~mm}$ from the tumor margin to indicate the safety margins. After submucosal injection of glycerol solution $(10 \%$ glycerol and $5 \%$ fructose; Chugai Pharmaceutical, Tokyo, Japan) containing a small amount of indigo carmine and epinephrine, a mucosal incision was made outside the marker dots. Hyaluronic acid solution was added to the glycerol solution being injected if mucosal elevation was insufficient because of ulceration of the lesion or massive fibrosis of the submucosal layer. After mucosal incision, the submucosal layer was dissected directly to obtain a perfect specimen, and complete en bloc resection was performed. Hemostatic forceps (HDB2422 W; Pentax, Tokyo, Japan) in soft coagulation mode were used to control bleeding during the procedure. In all cases, prophylactic coagulation of visible vessels on the mucosal defect was performed immediately after ESD with hemostatic forceps or with EZ Clips (HX-610-090/ HX-610-090S/HX-610-135; Olympus Medical Systems).

ESD was usually performed in conscious patients sedated with a mixture of diazepam $(5-20 \mathrm{mg})$ and pethidine hydrochloride (35-70). However, if the procedure was expected to take longer $2 \mathrm{~h}$, general anesthesia was administered.

Patients started drinking water and a liquid diet the day after the ESD procedure if there were no signs of perforation or post-ESD bleeding. A proton pump inhibitor was administered to all patients on the day of ESD, and use was regularly continued for 60 days after ESD. In most cases, second-look endoscopy was performed on day 7 after ESD, and the decision to discharge the patient from the hospital was made if there was no stigma of bleeding (Forrest type I or type IIa) on the artificial ESD ulcer. In cases in which massive intraprocedural bleeding occurred or was considered as high risk for post-ESD bleeding, second-look endoscopy was performed on day 1 or day 2 after ESD. If a clinical episode of melena or hematemesis occurred during the post-ESD period, emergency endoscopy was performed, with therapeutic endoscopic hemostasis, if necessary, with use of hemostatic forceps or hemostatic clips. The method used to achieve hemostasis was selected on the 
basis of the bleeding condition. Efforts to achieve hemostasis were continued until active bleeding had stopped for several seconds, including after flushing with water, or the visible vessels had disappeared.

\section{Management of antithrombotic treatment}

If patients were being treated with oral antithrombotic agents, such as low-dose aspirin, thienopyridine, or cilostazol, the prescribing physicians were consulted as to how best to manage antithrombotic therapy during the periESD period. In most patients who were taking antithrombotics before ESD and who were assessed as having low risk of cardiovascular events, aspirin use was discontinued 3-5 days before ESD, thienopyridine use was discontinued 5-7 days before ESD, and warfarin use was discontinued 3-4 days before ESD, whereas patients at high risk of cardiovascular events were either treated with intravenously administered heparin as an alternative or continued receiving their antiplatelet agent therapy. Unfractionated heparin was used as the heparin alternative therapy, and continuous administration of heparin was initiated and controlled to keep the activated partial thromboplastin time at 1.5 -fold to 2.5 -fold that of the control. Heparin therapy was stopped $6 \mathrm{~h}$ before ESD. Antithrombotic treatment was restarted as soon as possible when hemostasis was confirmed by the absence of symptoms of gastrointestinal bleeding or no significant decrease in hemoglobin level. In patients taking warfarin, heparin therapy was discontinued when the prothrombin time international normalized ratio reached approximately 1.5-2.5. For patients who were restarted on antiplatelet agent therapy, heparin therapy was discontinued on the same day.

\section{Definitions of post-ESD bleeding}

Post-ESD bleeding was defined as an episode of hematemesis/melena or a decrease in hemoglobin levels (more than $2 \mathrm{~g} / \mathrm{dL}$ ). All patients meeting this criterion underwent emergency esophagogastroduodenoscopy, and endoscopic hemostatic procedures were performed when active bleeding (Forrest type I) or stigmata of potential bleeding (Forrest type IIa) were observed. Preventive hemostasis for visible vessels without the clinical criterion of bleeding on second-look endoscopy was not included in post-ESD bleeding.

\section{Evaluation of resected specimens}

Gastric neoplasms were categorized according to their location (i.e., upper, middle, or lower third of the stomach). Tumor size and ulceration were determined histopathologically, and the size of the resected specimen was measured at its maximum diameter.

\section{Statistical analysis}

Unless indicated otherwise, data are expressed as the mean \pm standard deviation. Mean quantitative values among groups were compared statistically by analysis of variance followed by the $t$ test.

These categorical variables were compared statistically by the chi-squared test or Fisher's exact test in univariate analysis. Those variables with $P<0.05$ on univariate analysis were examined in multivariate logistic regression models. Odds ratios (ORs) and $95 \%$ confidence intervals (CIs) were calculated by logistic regression analysis to identify factors associated with postoperative bleeding. Two-tailed $P<0.05$ was considered significant. All data analyses were conducted with Stata version 11 (StataCorp, College Station, TX, USA).

\section{Results}

In all, 1781 patients were enrolled in the study; clinicopathologic characteristics of the patients are shown in Tables 1 and 2. The mean patient age was 69.0 years. Many patients had comorbidities, including cardiovascular disease $(13.5 \%)$ and central neurological disease $(7.8 \%)$, which required antithrombotic therapy. Of the 1781 patients, $253(14.2 \%)$ were being treated with antithrombotic agents. During the peri-ESD period, 186 of these 253 patients discontinued taking antithrombotic agents: 150 discontinued taking a single agent and 36 discontinued taking multiple agents. Of the remaining patients who were receiving antithrombotic therapy, 15 continued taking a single antiplatelet agent and 52 were switched to heparin therapy. Table 3 provides details of the antithrombotic agents whose use was discontinued or continued in all 253 patients. Heparin alternative therapy was administered to 52 patients: 40 patients $(76.9 \%)$ who had been taking an anticoagulant agent with $(n=17)$ or without $(n=23)$ other antithrombotics, five patients $(9.6 \%)$ who had been taking multiple antiplatelet agents, and seven patients $(13.5 \%)$ who had been taking a single antiplatelet agent.

Post-ESD bleeding occurred in 101 patients $(5.7 \%)$ in total. Relationships between post-ESD bleeding and various clinicopathologic factors were examined by univariate analysis (Table 1). Significant relationships were identified between post-ESD bleeding and six factors: cardiovascular disease, antithrombotic use, tumor location (upper and lower third of the stomach), tumor size ( $20 \mathrm{~mm}$ or greater), the presence of an ulcer in the tumor, and operation time (100 min or longer). With regard to antithrombotic 
Table 1 Clinicopathologic characteristics of the patients and univariate analysis of the relationship between post-endoscopic submucosal dissection $(E S D)$ bleeding and various clinicopathologic factors

\begin{tabular}{|c|c|c|c|c|c|}
\hline & $\begin{array}{l}\text { All patients } \\
(n=1781)\end{array}$ & $\begin{array}{l}\text { No bleeding } \\
(n=1680)\end{array}$ & $\begin{array}{l}\text { Bleeding } \\
(n=101)\end{array}$ & $\begin{array}{l}\text { Bleeding rate } \\
(\%)\end{array}$ & $P$ \\
\hline Males/females & $1377 / 404$ & $1298 / 382$ & $79 / 22$ & $5.7 / 5.4$ & 0.824 \\
\hline Age (years) & $69.0 \pm 9.4$ & $69.0 \pm 9.4$ & $67.7 \pm 10.1$ & & 0.154 \\
\hline \multicolumn{6}{|l|}{ Comorbidities } \\
\hline Central neurological disease & 139 & 126 & 13 & 9.4 & 0.051 \\
\hline Pulmonary disease & 130 & 118 & 12 & 9.2 & 0.068 \\
\hline Cardiovascular disease & 240 & 218 & 22 & 9.2 & 0.012 \\
\hline Renal disease/dialysis & $89 / 19$ & $83 / 16$ & $6 / 3$ & $6.7 / 15.8$ & 0.654 \\
\hline Hepatic disease/hepatic cirrhosis & $130 / 47$ & $119 / 44$ & $11 / 3$ & $8.5 / 6.4$ & 0.165 \\
\hline Hypertension & 663 & 624 & 39 & 5.9 & 0.766 \\
\hline Diabetes mellitus & 343 & 325 & 18 & 5.2 & 0.706 \\
\hline Antithrombotic user & 253 & 220 & 33 & 13.0 & $<0.001$ \\
\hline $\begin{array}{l}\text { Continued use of a single } \\
\text { antiplatelet agent }\end{array}$ & 15 & 14 & 1 & 6.7 & 0.585 \\
\hline $\begin{array}{l}\text { Discontinued use of a single } \\
\text { antithrombotic }\end{array}$ & 150 & 139 & 11 & 7.3 & 0.358 \\
\hline $\begin{array}{l}\text { Discontinued use of multiple } \\
\text { antithrombotics }\end{array}$ & 36 & 30 & 6 & 16.7 & 0.004 \\
\hline Heparin alternative therapy & 52 & 37 & 15 & 28.8 & $<0.001$ \\
\hline \multicolumn{6}{|l|}{ Tumor location } \\
\hline Upper third of the stomach & 323 & 313 & 10 & 3.1 & 0.027 \\
\hline Middle third of the stomach & 550 & 525 & 25 & 4.5 & 0.170 \\
\hline Lower third of the stomach & 908 & 842 & 66 & 7.3 & 0.003 \\
\hline \multicolumn{6}{|l|}{ Pathologic finding } \\
\hline Carcinoma/adenoma & $1566 / 215$ & $1473 / 207$ & $93 / 8$ & $5.9 / 3.7$ & 0.187 \\
\hline Tumor size (mm) & $20.1 \pm 15.6$ & $19.9 \pm 15.3$ & $24.5 \pm 19.0$ & & 0.004 \\
\hline Tumor size $\geqq 20 \mathrm{~mm}$ & 687 & 637 & 50 & 7.3 & 0.020 \\
\hline \multicolumn{6}{|l|}{ Tumor depth } \\
\hline Intramucosal & 1540 & 1450 & 90 & 5.8 & 0.424 \\
\hline Submucosal or deeper & 241 & 230 & 11 & 4.6 & \\
\hline Presence of ulcer in tumor & 265 & 243 & 22 & 8.3 & 0.045 \\
\hline Operation time (min) & $88.2 \pm 54.6$ & $87.1 \pm 53.7$ & $107.6 \pm 64.3$ & & $<0.001$ \\
\hline No. with $\mathrm{ESD}<100 \mathrm{~min} / \geqq 100 \mathrm{~min}$ & $1183 / 598$ & $1130 / 550$ & $53 / 48$ & $4.5 / 8.0$ & 0.002 \\
\hline
\end{tabular}

Unless indicated otherwise, the data are given as the mean \pm standard deviation or as the number of patients in each group

therapy, heparin alternative therapy $(P<0.001)$ and discontinuation of the use of multiple antithrombotic agents $(P=0.004)$ were significantly related to post-ESD bleeding. Tumor location in the lower third of the stomach was significantly associated with a high rate of post-ESD bleeding, whereas tumor location in the upper third of the stomach was associated with a low rate of bleeding.

Multivariate analysis was then performed on these factors to determine which factors remained associated with post-ESD bleeding (Table 4). Heparin alternative therapy, discontinuation of the use of multiple antithrombotic agents, tumor location in the lower third of the stomach, and long operation time (100 $\mathrm{min}$ or longer) were significantly related to post-ESD bleeding. Of these factors, the OR was higher for heparin alternative therapy (OR $10.04,95 \%$ CI 4.35-23.16) and discontinuation of the use of multiple antithrombotic agents (OR 5.44, $95 \% \mathrm{CI}$ 2.00-14.79).

Next, we examined relationships between clinical outcomes of ESD and subgroups on the basis of antithrombotic use (Table 2). If patients who were not using antithrombotic agents were set as the reference group, the ORs of post-ESD bleeding were significantly higher for patients receiving heparin alternative therapy (OR 8.70, $95 \%$ CI 4.56-16.6) and those who discontinued use of multiple antithrombotic agents (OR 4.29, $95 \%$ CI 1.73-10.66). Similarly, the ORs 
Table 2 Clinical characteristics and outcomes of gastric endoscopic submucosal dissection (ESD) according to antithrombotic use

\begin{tabular}{|c|c|c|c|c|c|c|}
\hline & \multirow{2}{*}{$\begin{array}{l}\text { All } \\
\text { patients }\end{array}$} & \multirow{2}{*}{$\begin{array}{l}\text { No } \\
\text { antithrombotic }\end{array}$} & \multirow{2}{*}{$\begin{array}{l}\text { Continued single } \\
\text { antiplatlet agent use }\end{array}$} & \multicolumn{2}{|c|}{ Discontinued antithrombotic use } & \multirow[t]{2}{*}{ Heparin } \\
\hline & & & & Single & Multiple & \\
\hline Patients & 1781 & 1528 & 15 & 150 & 36 & 52 \\
\hline Age (years) & $69.0 \pm 9.4$ & $68.1 \pm 9.4$ & $73.9 \pm 6.9$ & $74.0 \pm 7.8$ & $73.9 \pm 6.7$ & $75.6 \pm 6.9$ \\
\hline Males/females & $1377 / 404$ & $1162 / 366$ & $13 / 2$ & $130 / 20$ & $31 / 5$ & $41 / 11$ \\
\hline Absolute indication & $934(52.4 \%)$ & $805(52.7 \%)$ & $13(86.7 \%)$ & $72(48.0 \%)$ & $21(58.3 \%)$ & $23(44.2 \%)$ \\
\hline Expanded indication & $642(36.0 \%)$ & $549(35.9 \%)$ & $2(13.3 \%)$ & $61(40.7 \%)$ & $12(33.3 \%)$ & $18(34.6 \%)$ \\
\hline Outside of indication & $205(11.5 \%)$ & $174(11.4 \%)$ & $0(0 \%)$ & $17(11.3 \%)$ & $3(8.3 \%)$ & $11(21.2 \%)$ \\
\hline Post-ESD bleeding & $101(5.7 \%)$ & $68(4.5 \%)$ & $1(6.7 \%)$ & $11(7.3 \%)$ & $6(16.7 \%)$ & $15(28.8 \%)$ \\
\hline $\mathrm{OR}^{\mathrm{a}}$ & & 1.00 & $1.53(0.19-11.8)$ & $1.70(0.88-3.29)$ & $4.29(1.73-10.7)$ & $8.70(4.56-16.6)$ \\
\hline $\begin{array}{l}\text { Median timing of post-ESD } \\
\text { bleeding }^{\mathrm{b}} \text { (days) }\end{array}$ & $3(0-15)$ & $2(0-15)$ & $6(6-6)$ & $3(1-14)$ & $4.5(1-13)$ & $7(2-10)$ \\
\hline $\mathrm{CR}^{\mathrm{a}}$ & & 1.00 & $2.47(-5.07$ to 10.01$)$ & $2.47(0.04-4.90)$ & $2.30(-0.88$ to 5.49$)$ & $3.00(0.87-5.14)$ \\
\hline Blood transfusion & $18(1.0 \%)$ & $9(0.6 \%)$ & $0(0.0 \%)$ & $3(2.0 \%)$ & $2(5.6 \%)$ & $4(7.7 \%)$ \\
\hline $\mathrm{OR}^{\mathrm{a}}$ & & 1.00 & Not evaluated & $3.44(0.92-12.9)$ & $9.92(2.06-47.7)$ & $14.06(4.18-47.3)$ \\
\hline Perforation & $39(2.2 \%)$ & $34(2.22 \%)$ & $0(0 \%)$ & $4(2.7 \%)$ & $0(0 \%)$ & $1(1.9 \%)$ \\
\hline $\mathrm{OR}^{\mathrm{a}}$ & & 1.00 & Not evaluated & $1.17(0.41-3.34)$ & Not evaluated & $0.90(0.12-6.72)$ \\
\hline Hospital stay (days) & $10.7 \pm 7.6$ & $10.1 \pm 5.8$ & $13.2 \pm 8.6$ & $12.3 \pm 14.7$ & $13.4 \pm 7.9$ & $21.5 \pm 13.8$ \\
\hline $\mathrm{CR}^{\mathrm{a}}$ & & 1.00 & $3.13(-0.69$ to 6.88$)$ & $2.25(1.01-3.48)$ & $3.32(0.89-5.75)$ & $11.45(9.42-13.5)$ \\
\hline Thromboembolism after ESD & $1(0.06 \%)$ & $0(0 \%)$ & $0(0 \%)$ & $0(0 \%)$ & $0(0 \%)$ & $1(1.9 \%)$ \\
\hline
\end{tabular}

Unless indicated otherwise, data are given as the mean \pm standard deviation or as the number of patients in each group

$C I$ confidence interval, $C R$ coefficient of regression, $O R$ odds ratio

a The $95 \%$ confidence interval is given in parentheses

$\mathrm{b}$ The range is given in parentheses

of blood transfusion were significantly higher for patients receiving heparin alternative therapy (OR 14.06, $95 \%$ CI 4.18-47.3) and those who discontinued use of multiple antithrombotic agents (OR 9.92, $95 \%$ CI 2.06-47.7). Furthermore, the timing of post-ESD bleeding tended to be later in patients receiving heparin alternative therapy compared with patients who were not taking any antithrombotic agent (median day 7 vs day 2 after ESD; coefficient of regression $3.00,95 \%$ CI $0.87-5.14$ if patients not taking antithrombotic agents were set as the reference group). The length of hospital stay was almost doubled in patients receiving heparin alternative therapy compared with patients not taking any antithrombotic agent ( $21.5 \pm 13.8$ days vs $10.1 \pm 5.8$ days, respectively).

Perforation occurred in 39 patients $(2.2 \%)$. All perforations were cured without surgery by conservative treatment with intravenous administration of antibiotics, a proton pump inhibitor, and by withholding oral intake for a few days.

Thromboembolism during the peri-ESD period was observed in one patient who was switched to heparin therapy; left renal infarction occurred on day 7 after ESD when heparin alternative therapy and warfarin were administered simultaneously. One major hemorrhage other than gastrointestinal bleeding occurred in one patient receiving heparin alternative therapy in whom heparin therapy was not restarted; specifically, this patient experienced cerebral bleeding in an old cerebral infarction in the left hemisphere $12 \mathrm{~h}$ after completion of ESD. Thromboembolism and major bleeding other than gastrointestinal bleeding did not occur during the peri-ESD period in any patients who were not receiving heparin alternative therapy.

\section{Discussion}

The present study provides detailed information regarding the relationship between bleeding after gastric ESD and antithrombotic therapy in a large cohort of 1781 patients, including 253 patients $(14.1 \%)$ who were being treated with antithrombotic agents. Regardless of discontinuation or continuation of use of the drug, taking a single antiplatelet agent did not significantly alter the postoperative bleeding risk. In contrast, multivariate analysis identified that heparin alternative therapy and discontinuation of use of multiple antithrombotic agents significantly increased the risk of post-ESD bleeding. A possible explanation for this is that the antithrombotic effect of heparin alternative therapy and multiple antithrombotics is stronger than that of a single antithrombotic, and some antithrombotic effect 
Table 3 Details of the antithrombotic agents used in 253 patients

\begin{tabular}{|c|c|c|c|c|c|}
\hline \multirow[t]{2}{*}{ Antithrombotic type } & \multirow{2}{*}{$\begin{array}{l}\text { All patients } \\
(n=253)\end{array}$} & \multirow{2}{*}{$\begin{array}{l}\text { Continued single } \\
\text { antiplatelet agent use } \\
(n=15)\end{array}$} & \multicolumn{2}{|c|}{ Discontinued antithrombotic use } & \multirow{2}{*}{$\begin{array}{l}\text { Heparin } \\
(n=52)\end{array}$} \\
\hline & & & Single $(n=150)$ & Multiple $(n=36)$ & \\
\hline Aspirin & $100(39.5 \%)$ & $6(40.0 \%)$ & $90(60.0 \%)$ & - & $4(7.7 \%)$ \\
\hline Thienopyridine & $23(9.1 \%)$ & $4(26.7 \%)$ & $17(11.3 \%)$ & - & $2(3.8 \%)$ \\
\hline Cilostazol & $17(6.7 \%)$ & $1(6.7 \%)$ & $15(10.0 \%)$ & - & $1(1.9 \%)$ \\
\hline Warfarin & $45(17.8 \%)$ & - & $24(16.0 \%)$ & - & $21(40.4 \%)$ \\
\hline NOAC & $6(2.4 \%)$ & - & $4(2.7 \%)$ & - & $2(3.8 \%)$ \\
\hline Aspirin + thienopyridine ${ }^{\mathrm{a}}$ & $24(9.5 \%)$ & $4(26.7 \%)$ & - & $16(44.4 \%)$ & $4(7.7 \%)$ \\
\hline Aspirin + cilostazol & $13(5.1 \%)$ & $0(0 \%)$ & - & $12(33.3 \%)$ & $1(1.9 \%)$ \\
\hline Aspirin + warfarin & $17(7.1 \%)$ & $0(0 \%)$ & - & $6(16.7 \%)$ & $11(21.2 \%)$ \\
\hline Aspirin + NOAC & $1(0.4 \%)$ & $0(0 \%)$ & - & $0(0 \%)$ & $1(1.9 \%)$ \\
\hline Thienopyridine + cilostazol & $2(0.8 \%)$ & $0(0 \%)$ & - & $2(5.6 \%)$ & $0(0 \%)$ \\
\hline Thienopyridine + warfarin & $2(0.8 \%)$ & $0(0 \%)$ & - & $0(0 \%)$ & $2(3.8 \%)$ \\
\hline Cilostazol + warfarin & $1(0.4 \%)$ & $0(0 \%)$ & - & $0(0 \%)$ & $1(1.9 \%)$ \\
\hline Aspirin + thienopyridine + warfarin & $1(0.4 \%)$ & $0(0 \%)$ & - & $0(0 \%)$ & $1(1.9 \%)$ \\
\hline Aspirin + cilostazol + warfarin & $1(0.4 \%)$ & $0(0 \%)$ & - & $0(0 \%)$ & $1(1.9 \%)$ \\
\hline
\end{tabular}

Data show the number of patients in each group, with percentages in parentheses

NOAC novel oral anticoagulant

${ }^{a}$ Continued use of aspirin and discontinued use of thienopyridine during the peri-endoscopic submucosal dissection period

Table 4 Multivariate analysis of factors related to postendoscopic submucosal dissection bleeding

\begin{tabular}{lrrr}
\hline & OR & $95 \%$ CI & \multicolumn{1}{c}{$P$} \\
\hline Heparin alternative therapy & 10.04 & $4.35-23.16$ & $<0.001$ \\
Discontinued use of multiple antithrombotics & 5.44 & $2.00-14.79$ & 0.001 \\
Lower third of the stomach & 2.17 & $1.32-3.58$ & 0.002 \\
Operation time $\geqq 100$ min & 2.00 & $1.25-3.20$ & 0.004 \\
Presence of ulcer in tumor & 1.54 & $0.91-2.59$ & 0.108 \\
Tumor size $\geqq 20$ mm & 1.27 & $0.81-1.99$ & 0.303 \\
Cardiovascular disease & 0.91 & $0.46-1.79$ & 0.781 \\
Upper third of the stomach & 0.56 & $0.26-1.21$ & 0.138 \\
\hline
\end{tabular}

$C I$ confidence interval, $O R$ odds ratio may remain in the peri-ESD period in cases of discontinued use of multiple antithrombotics and cause post-ESD bleeding at a higher rate even if the use of antithrombotics is discontinued.

Compared with patients who were not receiving antithrombotic therapy, hemorrhage occurred later (on around day 7 after ESD) in patients receiving heparin alternative therapy. During the switch from heparin to warfarin, a certain degree of overlapping action of these two drugs might cause a stronger antithrombotic effect in a later period and consequently caused delayed bleeding.

One of the patients receiving bridging heparin therapy experienced a renal infarction during the period of heparin treatment. Thromboembolic events or major hemorrhage other than gastrointestinal bleeding was not observed in any patients in any other groups who were not receiving heparin alternative therapy. These data lead us to question whether heparin alternative therapy is truly appropriate for perioperative management of patients taking anticoagulants who are at high risk of thromboembolic events.

The American Society for Gastrointestinal Endoscopy [20] and the Japan Gastroenterological Endoscopy Society [21] guidelines recommend heparin alternative therapy in patients receiving warfarin during endoscopic procedures. However, a recent large randomized prospective trial [22] that enrolled 681 patients reported that heparin bridging therapy during implantation of cardiovascular implantable electronic devices was associated with a significantly higher rate of device-pocket hematoma compared with uninterrupted warfarin therapy $(16.0 \%$ vs $3.5 \%$, respectively) and no difference in the rate of thromboembolic events. Also, two meta-analyses [23, 24] 
supported this result. These findings suggest that one option in the perioperative management of gastric ESD is uninterrupted warfarin therapy rather than substitution of heparin for warfarin.

Another option may be the use of novel oral anticoagulants (NOACs) with or without short-term interruption. All NOACs are rapid-acting agents, and so the anticoagulation-off window could be shorter, even in the case of interrupted use. Although the number of patients was limited in the present study, post-ESD bleeding did not occur in the five patients taking NOACs with short-term discontinuation. However, further data are necessary before the use of NOACs can be considered as an appropriate alternative for patients taking warfarin.

The present study showed that a single antiplatelet agent did not significantly affect the postoperative bleeding risk, regardless of whether its use was discontinued or continued. These findings are compatible with those of Sanomura et al. [25] and Lim et al. [17]. So, in patients at moderate to high risk of thromboembolism, gastric ESD with uninterrupted single antiplatelet treatment during the perioperative period could be an acceptable management option [26, 27].

There are several limitations in this study. Firstly, this study is of a retrospective design from a single high-volume center of endoscopy, and thus the results obtained need to be confirmed by further studies of prospective type. The management of antithrombotic agents for treatment of gastric ESD patients was not established previously because of the chronological trend and introduction of guidelines. Antithrombotic therapy is so diverse because of the many different drugs and many combinations of them as shown in Table 3 that the categorization of antithrombotic therapy was complicated. To avoid excessive subdivision of antithrombotic users, we tentatively classified them into four categories: continued use of a single antiplatelet agent, discontinued use of a single antithrombotic, discontinued use of multiple antithrombotics, and heparin alternative therapy. As a result, each category was not uniform but included users taking different drugs or different combinations of antithrombotics (Table 3). The validity of the categorization of antithromotic users should be verified by further studies. Another limitation is that we could not evaluate the relationship between post-ESD bleeding and the time at which antithrombotic use was restarted. The restarting times were too broad to set a clear threshold or criterion for the restarting time for assessment if it influenced the risk of post-ESD bleeding.

In conclusion, perioperative management of anticoagulation is a challenging clinical issue that requires balancing the risk of acute thromboemobolism against the risk of perioperative bleeding. Gastric ESD may be performed in patients taking a single antiplatelet agent regardless of whether use of the drug is continued or discontinued.
Because heparin alternative therapy significantly increases post-ESD bleeding risk and may not decrease the risk of thromboembolic and cardiovascular events, other options should be considered, including warfarin use or the use of NOACs.

Acknowledgment We thank Mitsuyoshi Urashima (Division of Molecular Epidemiology, Jikei University, Tokyo, Japan) for his insightful comments and advice on analyses in this study.

\section{Compliance with ethical standards}

Conflict of interest The authors declare that they have no conflict of interest.

Ethical standards All procedures followed were in accordance with the ethical standards of the responsible committee on human experimentation (institutional and national) and with the Helsinki Declaration of 1964 and later versions. Informed consent or substitute for it was obtained from all patients for their being included in the study.

\section{References}

1. Oka S, Tanaka S, Kaneko I, Mouri R, Hirata M, Kawamura T, Yoshihara M, Chayama K. Advantage of endoscopic submucosal dissection compared with EMR for early gastric cancer. Gastrointest Endosc. 2006;64:877-83.

2. Watanabe K, Ogata S, Kawazoe S, et al. Clinical outcomes of EMR for gastric tumors: historical pilot evaluation between endoscopic submucosal dissection and conventional mucosal resection. Gastrointest Endosc. 2006;63:776-82.

3. Lian J, Chen S, Zhang Y, Qiu F. A meta-analysis of endoscopic submucosal dissection and EMR for early gastric cancer. Gastrointest Endosc. 2012;76:763-70.

4. Hoteya S, Iizuka T, Kikuchi D, Yahagi N. Benefits of endoscopic submucosal dissection according to size and location of gastric neoplasm, compared with conventional mucosal resection. J Gastroenterol Hepatol. 2009;24:1102-6.

5. Yokoi C, Gotoda T, Hamanaka H, et al. Endoscopic submucosal dissection allows curative resection of locally recurrent early gastric cancer after prior endoscopic mucosal resection. Gastrointest Endosc. 2006;64:212-8.

6. Oda I, Suzuki H, Nonaka S, Yoshinaga S. Complications of gastric endoscopic submucosal dissection. Dig Endosc. 2013;25(Suppl 1):71-8.

7. Toyonaga T, Man-i M, East JE, Nishino E, Ono W, Hirooka T, et al. 1,635 Endoscopic submucosal dissection cases in the esophagus, stomach, and colorectum: complication rates and long-term outcomes. Surg Endosc. 2013;27:1000-8.

8. Saito Y, Uraoka T, Matsuda T, Emura F, Ikehara H, Mashimo Y, et al. Endoscopic treatment of large superficial colorectal tumors: a case series of 200 endoscopic submucosal dissections (with video). Gastrointest Endosc. 2007;66:966-73.

9. Fujisiro M, Yahagi N, Kakusima S, et al. Out comes endoscopic submucosal dissection for colorectal epithelial neoplasms in 200 consecutive cases. Clin Gastroenterol Hepatol. 2007;5:678-83.

10. Saito Y, Uraoka T, Yamaguchi Y, Hotta K, Sakamoto N, Ikematsu $\mathrm{H}$, et al. A prospective, multicenter study of $1111 \mathrm{col}-$ orectal endoscopic submucosal dissections (with video). Gastrointest Endosc. 2010;72:1217-25.

11. Terasaki M, Tanaka S, Shigita K, Asayama N, Nishiyama S, Hayashi $\mathrm{N}$, et al. Risk factors for delayed bleeding after 
endoscopic submucosal dissection for colorectal neoplasms. Int $\mathbf{J}$ Colorectal Dis. 2014;29(7):877-82.

12. Isomoto $\mathrm{H}$, Yamaguchi $\mathrm{N}$, Minami $\mathrm{H}$, Nakao K. Management of complications associated with endoscopic submucosal dissection/ endoscopic mucosal resection for esophageal cancer. Dig Endosc. 2013;25(Suppl 1):29-38.

13. Kagemoto K, Oka S, Tanaka S, Miwata T, Urabe Y, Sanomura Y, et al. Clinical outcomes of endoscopic submucosal dissection for superficial Barrett's adenocarcinoma. Gastrointest Endosc. 2014;80(2):239-45.

14. Takizawa K, Oda I, Gotoda $\mathrm{T}$, et al. Routine coagulation of visible vessels may prevent delayed bleeding after endoscopic submucosal dissection-an analysis of risk factors. Endoscopy. 2008;40:179-83.

15. Tsuji $\mathrm{Y}$, Ohata $\mathrm{K}$, Ito $\mathrm{T}$, et al. Risk factors for bleeding after endoscopic submucosal dissection for gastric lesions. World $\mathbf{J}$ Gastroenterol. 2010;16:2913-7.

16. Okada K, Yamamoto Y, Kasuga A, et al. Risk factors for delayed bleeding after endoscopic submucosal dissection for gastric neoplasm. Surg Endosc. 2010;25:98-107.

17. Lim JH, Kim SG, Kim JW, et al. Do antiplatelets increase the risk of bleeding after endoscopic submucosal dissection of gastric neoplasms? Gastrointest Endosc. 2012;75:719-27.

18. Koh R, Hirasawa K, Yahara S, et al. Antithrombotic drugs are risk factors for delayed postoperative bleeding after endoscopic submucosal dissection for gastric neoplasms. Gastrointest Endosc. 2013;78:476-83.

19. Japanese Gastric Cancer Association. Japanese gastric cancer treatment guidelines 2010 (ver. 3). Gastric Cancer. 2011;14: $113-23$.
20. ASGE Standards of Practice Committee, Anderson MA, BenMenachem T, et al. Management of antithrombotic agents for endoscopic procedures. Gastrointest Endosc. 2009;70:1060-70.

21. Fujimoto K, Fujishiro M, Kato M, et al. Guidelines for gastroenterological endoscopy in patients undergoing antithrombotic treatment. Dig Endosc. 2014;26:1-14.

22. Birnie DH, Healey JS, Wells GA, et al. Pacemaker or defibrillator surgery without interruption of anticoagulation. N Engl J Med. 2013;30(368):2084-93.

23. Siegal D, Yudin J, Kaatz S, et al. Periprocedural heparin bridging in patients receiving vitamin $\mathrm{K}$ antagonists: systematic review and meta-analysis of bleeding and thromboembolic rates. Circulation. 2012;126:1630-9.

24. Ghanbari H, Phard WS, Al-Ameri H, et al. Meta-analysis of safety and efficacy of uninterrupted warfarin compared to heparin-based bridging therapy during implantation of cardiac rhythm devices. Am J Cardiol. 2012;110:1482-8.

25. Sanomura Y, Oka S, Tanaka S, et al. Continued use of low-dose aspirin does not increase the risk of bleeding during or after endoscopic submucosal dissection for early gastric cancer. Gastric Cancer. 2014;17:489-96.

26. Cho SJ, Choi IJ, Kim CG, et al. Aspirin use and bleeding risk after endoscopic submucosal dissection in patients with gastric neoplasms. Endoscopy. 2012;44:114-21.

27. Boustière C, Veitch A, Vanbiervliet G, et al. Endoscopy and antiplatelet agents. European Society of Gastrointestinal Endoscopy (ESGE) guideline. Endoscopy. 2011;43:445-58. 